\title{
Mechanical stiffness of TMJ condylar cartilage increases after artificial aging by ribose
}

Citation for published version (APA):

Mirahmadi, F., Koolstra, J. H., Lobbezoo, F., van Lenthe, H., Ghazanfari, S., Snabel, J., Stoop, R., \& Everts, V. (2018). Mechanical stiffness of TMJ condylar cartilage increases after artificial aging by ribose. Archives of Oral Biology, 87, 102-109. https://doi.org/10.1016/j.archoralbio.2017.12.010

Document status and date:

Published: 01/03/2018

DOI:

10.1016/j.archoralbio.2017.12.010

Document Version:

Publisher's PDF, also known as Version of record

Document license:

Taverne

\section{Please check the document version of this publication:}

- A submitted manuscript is the version of the article upon submission and before peer-review. There can be important differences between the submitted version and the official published version of record.

People interested in the research are advised to contact the author for the final version of the publication, or visit the DOI to the publisher's website.

- The final author version and the galley proof are versions of the publication after peer review.

- The final published version features the final layout of the paper including the volume, issue and page numbers.

Link to publication

\footnotetext{
General rights rights.

- You may freely distribute the URL identifying the publication in the public portal. please follow below link for the End User Agreement:

www.umlib.nl/taverne-license

Take down policy

If you believe that this document breaches copyright please contact us at:

repository@maastrichtuniversity.nl

providing details and we will investigate your claim.
}

Copyright and moral rights for the publications made accessible in the public portal are retained by the authors and/or other copyright owners and it is a condition of accessing publications that users recognise and abide by the legal requirements associated with these

- Users may download and print one copy of any publication from the public portal for the purpose of private study or research.

- You may not further distribute the material or use it for any profit-making activity or commercial gain

If the publication is distributed under the terms of Article $25 \mathrm{fa}$ of the Dutch Copyright Act, indicated by the "Taverne" license above, 


\title{
Mechanical stiffness of TMJ condylar cartilage increases after artificial aging by ribose
}

\author{
Fereshteh Mirahmadi ${ }^{\mathrm{a}, \mathrm{b}, *}$, Jan Harm Koolstra ${ }^{\mathrm{a}}$, Frank Lobbezoo ${ }^{\mathrm{c}}$, G.Harry van Lenthe ${ }^{\mathrm{b}}$, \\ Samaneh Ghazanfari ${ }^{\mathrm{a}, \mathrm{d}, \mathrm{e}}$, Jessica Snabel ${ }^{\mathrm{f}}$, Reinout Stoop ${ }^{\mathrm{f}}$, Vincent Everts ${ }^{\mathrm{a}}$ \\ a Department of Oral Cell Biology and Functional Anatomy, Academic Centre for Dentistry Amsterdam (ACTA), University of Amsterdam and Vrije Universiteit \\ Amsterdam, Amsterdam Movement Sciences, Amsterdam, The Netherlands \\ biomechanics section, Department of Mechanical Engineering, KU Leuven, Leuven, Belgium \\ ${ }^{\mathrm{c}}$ Department of Oral Kinesiology, Academic Centre for Dentistry Amsterdam (ACTA), University of Amsterdam and Vrije Universiteit Amsterdam, Amsterdam, The \\ Netherlands \\ d Aachen-Maastrciht Institute for Biobased Materials, Faculty of Humanities and Sciences, Maastricht University, Maastricht, The Netherlands \\ e Department of Orthopedic Surgery, Vrije Universiteit Medical Center, Amsterdam, The Netherlands \\ ${ }^{\mathrm{f}}$ TNO Metabolic Health Research, Leiden, The Netherlands
}

\section{A R T I C L E I N F O}

\section{Keywords:}

Temporomandibular joint

Cartilage

Collagen crosslinks

Stiffness

\begin{abstract}
A B S T R A C T
Objective: Aging is accompanied by a series of changes in mature tissues that influence their properties and functions. Collagen, as one of the main extracellular components of cartilage, becomes highly crosslinked during aging. In this study, the aim was to examine whether a correlation exists between collagen crosslinking induced by artificial aging and mechanical properties of the temporomandibular joint (TMJ) condyle. To evaluate this hypothesis, collagen crosslinks were induced using ribose incubation.

Methods: Porcine TMJ condyles were incubated for 7 days with different concentrations of ribose. The compressive modulus and stiffness ratio (incubated versus control) was determined after loading. Glycosaminoglycan and collagen content, and the number of crosslinks were analyzed. Tissue structure was visualized by microscopy using different staining methods.

Results: Concomitant with an increasing concentration of ribose, an increase of collagen crosslinks was found. The number of crosslinks increased almost 50 fold after incubation with the highest concentration of ribose. Simultaneously, the stiffness ratio of the samples showed a significant increase after incubation with the ribose. Pearson correlation analyses showed a significant positive correlation between the overall stiffness ratio and the crosslink level; the higher the number of crosslinks the higher the stiffness.

Conclusion: The present model, in which ribose was used to mimic certain aspects of age-related changes, can be employed as an in vitro model to study age-related mechanical changes in the TMJ condyle.
\end{abstract}

\section{Introduction}

Collagen is the main component of the extracellular matrix (ECM) of connective tissues like bone and cartilage. Its molecules have helical structures which pack together to form collagen fibrils in fiber-type collagens (Ghazanfari, Khademhosseini, \& Smit, 2016; Lodish et al., 2000; Panwar et al., 2015). These fibrils progressively rearrange and crosslink at the inter-fibrillar level to provide structural integrity needed by a tissue for proper remodeling and load-bearing capacity (Wilson et al., 2014). Every change in molecular or structural organization of collagen caused by development, pathological conditions, or aging, has an impact on collagen's contributions to tissue function (Odetti et al., 2000; Panwar et al., 2015; Scharf et al., 2013; Wilson et al., 2014).

Aging is accompanied by a series of cellular, molecular, and structural changes in the mature tissues that ultimately influence their properties and functions (Panwar et al., 2015). Non-reversible collagen crosslinking is a prominent change in the ECM during aging. By altering the mechanical properties of collagen, it could result in an age-related degenerative effect on tissue maintenance (Ait-Belkacem et al., 2012; Bai, Phua, Hardt, Cernadas, \& Brodsky, 1992; Brüel \& Oxlund, 1996; Tang, Zeenath, \& Vashishth, 2007). Such age-related changes are

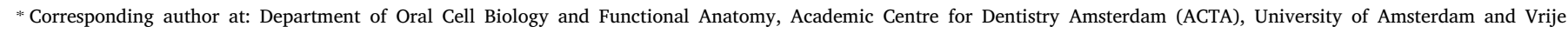
Universiteit Amsterdam, Amsterdam Movement Sciences, Amsterdam, The Netherlands.

E-mail addresses: f.mirahmadi@acta.nl (F. Mirahmadi), j.koolstra@acta.nl (J.H. Koolstra), f.lobbezoo@acta.nl (F. Lobbezoo), harry.vanlenthe@kuleuven.be (G.H. van Lenthe), samaneh.ghazanfari@maastrichtuniversity.nl (S. Ghazanfari), jessica.snabel@tno.nl (J. Snabel), reinout.stoop@tno.nl (R. Stoop), v.everts@acta.nl (V. Everts). 
thought to play a key role in the etiology of osteoarthritis (OA) which is characterized by progressive destruction of cartilage (Bank, Bayliss, Lafeber, Maroudas, \& Tekoppele, 1998; Basser, Schneiderman, Bank, Wachtel, \& Maroudas, 1998). Mechanical loading is considered a dominant factor for the onset or progression of cartilage damage. It has been shown that the age-related increase of collagen crosslinking increased tissue stiffness. This was considered to make the tissue more susceptible to mechanically-induced damage (Bourne, Lippell, \& Torzilli, 2014).

Collagen crosslinking often occurs due to enzymatic and/or nonenzymatic reactions. Enzymatic crosslinking mainly occurs during development and maturation. Non-enzymatic crosslinking reactions can take place due to aging-associated modifications and certain diseases (Wilson et al., 2014). These reactions, called glycation, happen in the presence of a reducing sugar and lead to the production of advanced glycation end-products (AGEs) in the tissue (Brüel \& Oxlund, 1996; DeGroot et al., 1999; Panwar et al., 2015). When AGEs are produced, they remain in the tissue until it is renewed. Cartilaginous collagen found in the joints has an extremely slow turnover rate and remains in the tissue after maturation without renewing (Verzijl et al., 2000). As a result, long-term accumulation of AGEs in the joints happens at older age (Bank et al., 1998; DeGroot et al., 1999; DeGroot et al., 2001b). Such an accumulation of AGEs would also happen in young adults due to the presence of extra sugar in the body in diabetes (Illien-Junger et al., 2013; Kohn, Cerami, \& Monnier, 1984; Odetti et al., 2000). Resembling the same condition, the excessive exposure of tissue to sugar has been used in vivo and ex vivo, as a method for the induction of artificial aging (DeGroot et al., 2001a, 2001b; Verzijl et al., 2002; Vos et al., 2012a). Pentosidine, a crosslink between arginine and lysine residues in collagen molecules, is a well-characterized and reliable measure of AGEs (Bank et al., 1998; Sell \& Monnier, 1989).

The effect of this artificial aging has been studied specifically on mechanical properties of ECM in different types of tissues including bone (Panwar et al., 2015; Willems et al., 2014), hyaline cartilage (Bank et al., 1998; Chen et al., 2002; Verzijl et al., 2002), and tendon (Reddy, 2004; Reddy, Stehno-Bittel, \& Enwemeka, 2002). It has also been utilized to study aging effects as the main risk factor for OA (Verzijl et al., 2002; Vos et al., 2012a; Willett, Kandel, De Croos, Avery, \& Grynpas, 2012). There is, however, no study in the literature on the effect of such a crosslinking induction on cartilage of the temporomandibular joint (TMJ).

In the present study, the aim was to examine whether a correlation exists between collagen crosslinking induced by artificial aging and mechanical properties of the TMJ condyle. Evaluation of TMJ cartilage is of particular interest because the TMJ condyle is covered with fibrocartilage rather than hyaline cartilage which cover other articular joints (Athanasiou, Almarza, Detamore, \& Kalpakci, 2009; Koolstra, 2002). It has a different cartilaginous structure and composition as compared to articular cartilage. Interestingly, in the regeneration of damaged hyaline cartilage, it is replaced by fibrocartilage containing collagen type I. This is generally considered a material of inferior quality at these locations, while in the TMJ it performs well under various loading conditions. The TMJ condyle of the porcine was selected on the basis of its similarities to the human jaw joint, especially in its mechanical characterization (Herring, 2003).

\section{Materials and methods}

\subsection{Sample preparation}

The heads of young pigs (aged 6-8 months old, gender not known) were collected from a local slaughterhouse. The left and right TMJ condyles were dissected within $12 \mathrm{~h}$ after sacrifice, and stored at $-20^{\circ} \mathrm{C}$. The dissected condyles were inspected visually to exclude the ones with gross abnormality, such as vascularization and fibrillation of the surface. In total, 24 condyles were used for this study.

\subsection{Crosslinking induction}

The condyles were divided into four groups: three groups for incubation with different concentrations of ribose and one control group. For each incubation group, five condyles were used (all from the right side of the mandibles); for the control group, nine condyles (all from the left side of the mandibles). For crosslinking induction, intact condyles were incubated in phosphate buffered saline (PBS) containing 125, 250, or $500 \mathrm{mM}$ ribose, a protease-inhibitor (PI) cocktail $(2 \mathrm{mM}$ Ethylenediaminetetraacetic acid; $5 \mathrm{mM}$ benzamidine; $10 \mathrm{mM}$ N-ethylmaleimide; $1 \mathrm{mM}$ phenylmethylsulfonyl fluoride (Kim, Wong, Helfrick, Thomas, \& Athanasiou, 2003)), and sodium azide $0.02 \%$ for 7 days at $37^{\circ} \mathrm{C}$. These groups were labeled as $R 125, R 250$, and $R 500$, respectively. The control samples were incubated in the same condition but without ribose. PI was added to minimize tissue degradation and sodium azide to prevent bacterial growth during the incubation time. For the next steps of the study, five regions per condyle were examined, i.e., central, medial, lateral, posterior, and anterior.

\subsection{Mechanical characterization}

For the mechanical loading, a compression loading test was performed by using a custom-made instrument equipped with a $25 \mathrm{~N}$ loadcell (Fazaeli, Ghazanfari, Everts, Smit, \& Koolstra, 2016). A rigid cylindrical indenter with a diameter of $4 \mathrm{~mm}$ was used for loading. This apparatus produces cyclic displacements of an indenter and simultaneously measures the compressive reaction force. The average thickness of each region was measured prior to loading using micro-CT scanning as described in a previous study (Mirahmadi, Koolstra, Lobbezoo, van Lenthe, \& Everts, 2017). To locate each region of interest perpendicular to the cylindrical indenter, the condyles were fixed in a container with adjustable tilting capability. The container was filled with PBS containing PI during the test. A tare load of $0.2 \mathrm{~N}$ was introduced to each region to maintain proper loading plate contact, followed by $5 \mathrm{~min}$ of relaxation time. Afterwards, 60 cycles of $1 \%$ strain at a frequency of $1 \mathrm{~Hz}$ were applied as preconditioning, followed by 5 min relaxation time. Thereafter, the condyle was cyclically loaded at a strain level of $5 \%$ for 20 cycles at $1 \mathrm{~Hz}$. It has been shown that 10 cycles of loading would be enough for TMJ disc to reach a steady state (Tanaka et al., 2002). Force-displacement curves were used to calculate stress-strain values using the initial thickness of each region and the cross-sectional area of the indenter. Instantaneous modulus $\left(\mathrm{E}_{\text {Ins }}\right)$ was calculated from the peak stress of the first cycle of loading. Steady state modulus $\left(E_{S t}\right)$ was similarly calculated from the average peak stresses of the last five cycles. Representative stress-strain curves from different groups are shown in Fig. 1.

\subsection{Biochemical analyses}

To examine the effect of crosslinking induction on biochemical properties, a plug of $4 \mathrm{~mm}$ was punched out from each mechanicallyloaded region of the condyles. All plugs were weighed and lyophilized overnight; the dry weight (DW) was measured afterward to calculate water content.

To measure the amount of GAG, about $2 \mathrm{mg}$ of the dried samples were incubated in papain digestion buffer at $60^{\circ} \mathrm{C}$ overnight and used for colorimetric quantification after reaction with dimethyl methylene blue (DMMB) (Ghazanfari et al., 2015). The GAG values were normalized to the tissue dry weight.

One portion of the digested sample was hydrolyzed with $6 \mathrm{M} \mathrm{HCl}$ at $95{ }^{\circ} \mathrm{C}$ for $20 \mathrm{~h}$, dried overnight, and used for the quantification of hydroxyproline (Hyp) and pentosidine (Pen) as measures of collagen content and of the number of collagen crosslinks, respectively. The amount of Hyp was measured following neutralization and a reaction with chloramine-T and dimethyl amino-benzaldehyde (Paul et al., 2013). To determine the collagen content, it was assumed that Hyp 


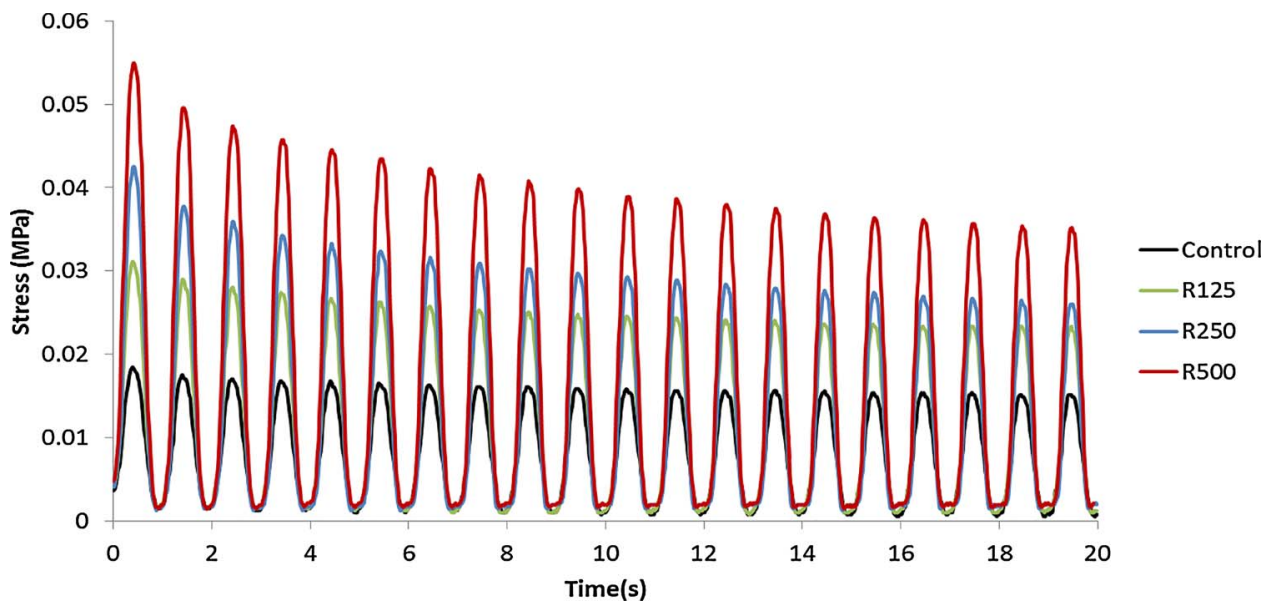

Fig 1. Representative stress-strain curves of control and treated groups from the posterior region.

comprises approximately $10 \%$ of the collagen weight (Reddy et al., 2002).

For the determination of the Pen level, high-performance liquid chromatography (HPLC) was used as described in detail elsewhere (Bank, Jansen, Beekman, \& te Koppele, 1996). The number of Pen crosslinks were determined and expressed as mole per mole collagen, assuming 300 Hyp residues per triple-helical of collagen molecule and a molecular weight of 300,000 g/mol (DeGroot et al., 1999; Vos et al., 2012b).

\subsection{Microscopy}

The plugs adjacent to those used for the biochemical analysis from all regions were fixed in 4\% formalin and used for histology. Cryosections with the thickness of $10 \mu \mathrm{m}$ were stained with SafraninO/Fast green and Picrosirius red. To eliminate the possible effect of sectioning and processing on the structure of collagen fibers, two pieces with a thickness of approximately $1 \mathrm{~mm}$ from the central region of one sample incubated with the highest concentration of ribose (R500) and another sample from the control group were stained with collagen type I and II antibodies (see Supplementary material for more detail). Confocal microscopy was used to make the images from thick slices.

\subsection{Statistical analyses}

To analyze the effect of ribose incubation and region on mechanical and biochemical properties, two-way analyses of variance (ANOVA) with LSD post-hoc test with the assumption of normal distribution of data were performed. Linear regression with Pearson correlation analysis was conducted to assess the correlation between the ribose concentration and the quantified parameters as well as the correlation between pentosidine and stiffness. All values are reported as mean \pm standard deviation. The statistical tests were carried out using SPSS 23 for Windows (SPSS Inc., Chicago, IL, USA), a $\mathrm{p}<.05$ was considered statistically significant.

\section{Results}

\subsection{Crosslinking induction}

Collagen crosslinking increased with the amount of ribose added to the samples. The condyles incubated with a high concentration of ribose, i.e., R250 and R500 showed a significant increase in the pentosidine (Pen) level (Fig. 2B); being almost 50-fold after incubation with R500. Linear regression analysis demonstrated a significant positive correlation between ribose concentration and Pen level. The increasing trend of Pen with ribose concentration was similar for all regions (Fig. 2A).

\subsection{Mechanical properties}

When ribose concentration increased, there was an increasing trend in stiffness as defined by instantaneous and steady state moduli $\left(E_{\text {Ins }}\right.$ and $\mathrm{E}_{\mathrm{St}}$ ). This was apparent for all regions (Fig. 3A, D). Statistical analyses revealed the absence of a statistically significant interaction between concentration and region on compressive moduli $(\mathrm{p}=0.954$ for instantaneous and $\mathrm{p}=.708$ for steady state moduli). The anterior regions showed the lowest stiffness for both incubated and control samples; posterior and central regions were the stiffest regions (Fig. 3A, D). A general stiffness ratio was calculated by dividing the stiffness of the incubated group with the average stiffness of the control group. Linear regression revealed significant correlations between general stiffness ratios and the ribose concentration (Fig. 3B, E). Linear regression also showed significant correlations between general stiffness ratios and Pen increase $\left(R=0.308\right.$ for general $E_{\text {Ins }}$ ratio and $R=0.265$ for general $\mathrm{E}_{\mathrm{St}}$ ratio, both $\mathrm{p}<.01$; Fig. 3C, F). An almost 50 -fold increase in cartilage Pen levels increased the general $\mathrm{E}_{\text {Ins }}$ ratio by about 1.5-fold from the control to R500.

\subsection{Biochemical analyses}

GAG content results demonstrated no differences among the groups with respect to regions (Fig. 4A). However, when all regions for each condyle were grouped on the basis of the ribose incubation (Fig. 4B), GAG concentration negatively correlated with ribose. This reduction was significant for condyles incubated with the highest ribose concentration, i.e., from $8.6 \pm 1.0 \mu \mathrm{g} / \mathrm{mg}$ DW for the R500 to $7.2 \pm 0.4 \mu \mathrm{g} / \mathrm{mg}$ DW for the control group.

With respect to the amount of collagen, no significant difference was found between the various regions (Fig. 5A). The results also showed that less collagen was measured when the concentration of ribose increased (Fig. 5B). The reduction of collagen was significant for the R500 group when compared to the control group.

\subsection{Microscopy}

Histology showed that the TMJ condylar cartilage was covered with a dense collagenous layer (Fig. 6A-D). When the concentration of ribose increased, spaces appeared within the collagenous matrix (arrows in Figs. 6 and 7). In the control group, collagen fibers in the superficial layer were aligned parallel to the surface (Fig. 6E). However, this parallel orientation changed following the incubation with ribose. As it is shown in Fig. 6 (panels E-H), collagen fibers were oriented in different directions when the concentration of ribose was increased, being most pronounced in the R500 group (Fig. 6H). This was confirmed with immunostaining when thicker sections of the central region from the control group and the R500 group were stained with collagen type I and 

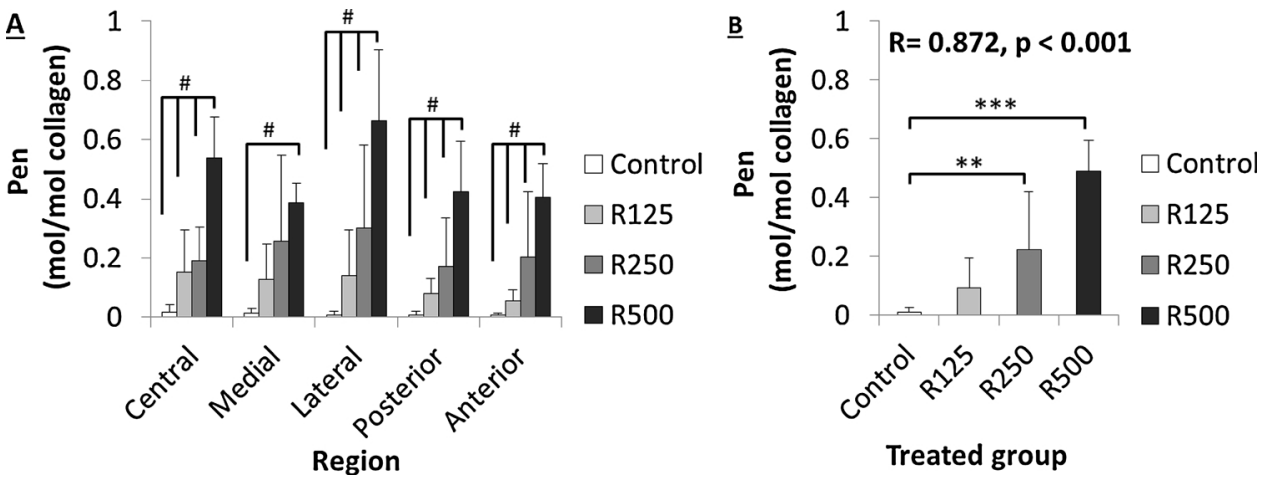

Fig. 2. Pentosidine (Pen) amount of different regions and ribose concentrations. Regional (A) and overall (B) Pen amount for different ribose concentrations Pen level increased significantly after ribose treatment in all region; \# shows significant differences between R500 and other groups with one-way ANOVA). There was also a significant positive correlation between overall Pen content and ribose concentration (Pearson correlation analyses). ** $\mathrm{p}<.01,{ }^{* * *} \mathrm{p}<.001$ significantly different from the control group with one-way ANOVA.
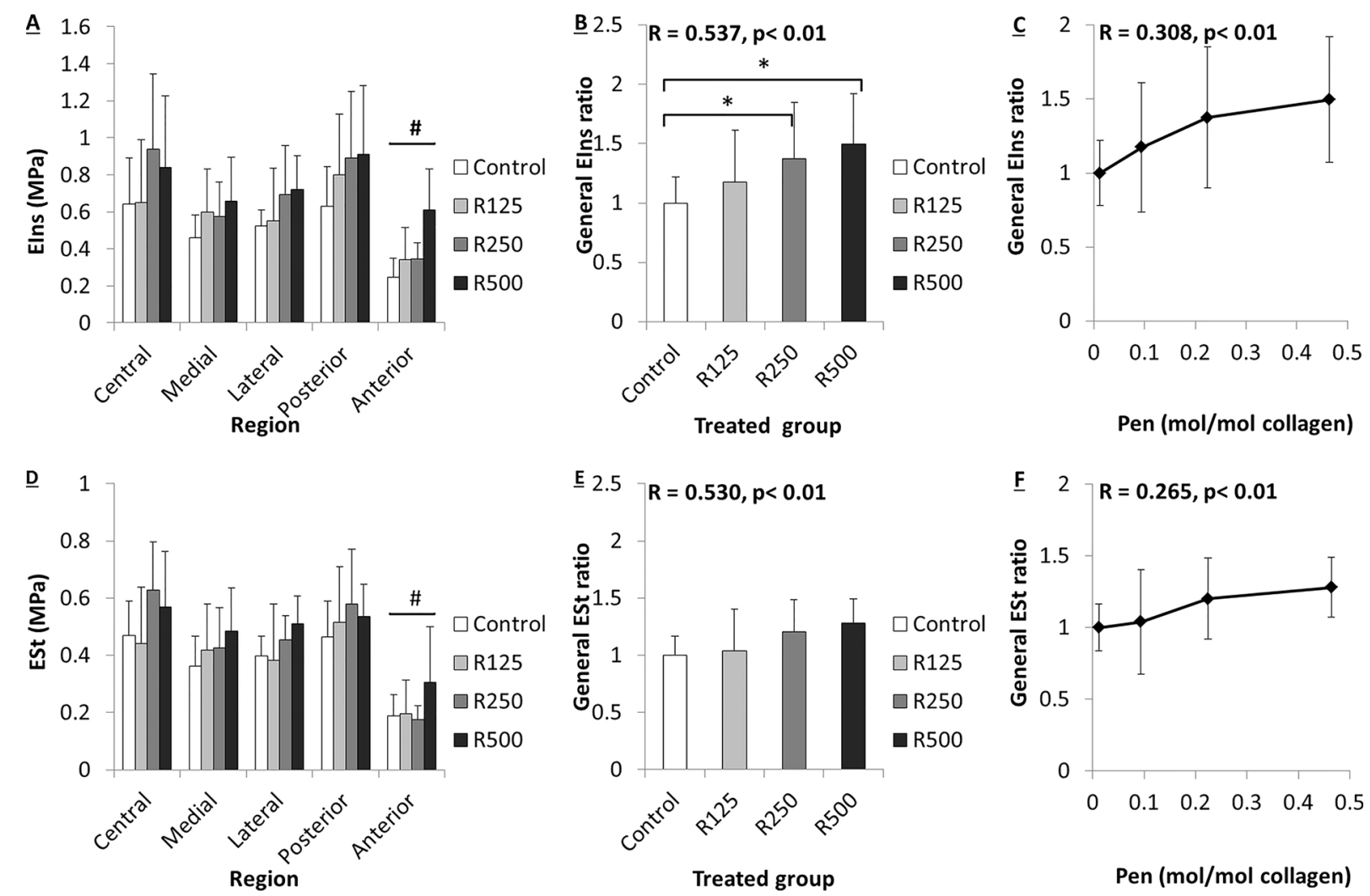

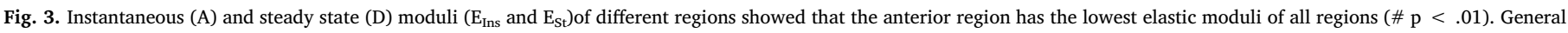

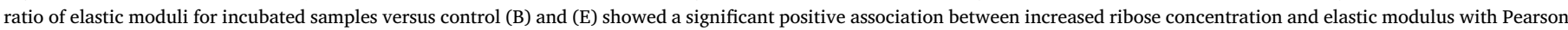

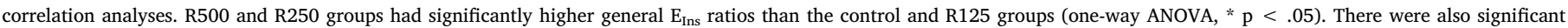
positive correlations between Pen amount and both general ratios with Pearson correlation analyses (C and F).
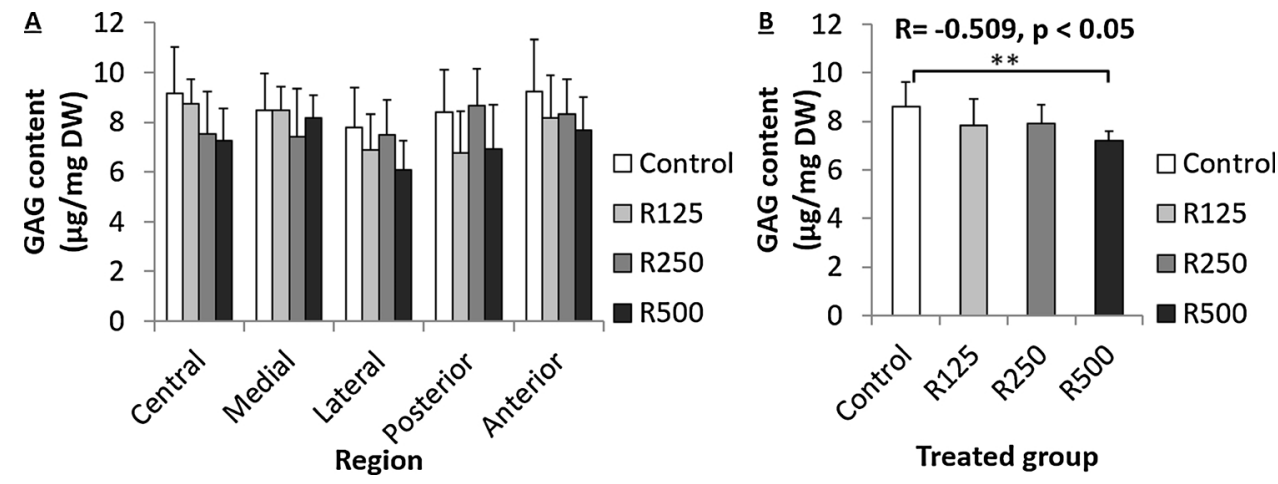

Fig. 4. GAG amount of different regions. Regional (A) and overall (B) GAG content for different ribose concentrations. There was a significant negative correlation between overall GAG content and ribose concentration (Pearson correlation analysis). GAG content decreased significantly after incubation with R500 (one-way ANOVA, ** $\mathrm{p}<.01$ ). 


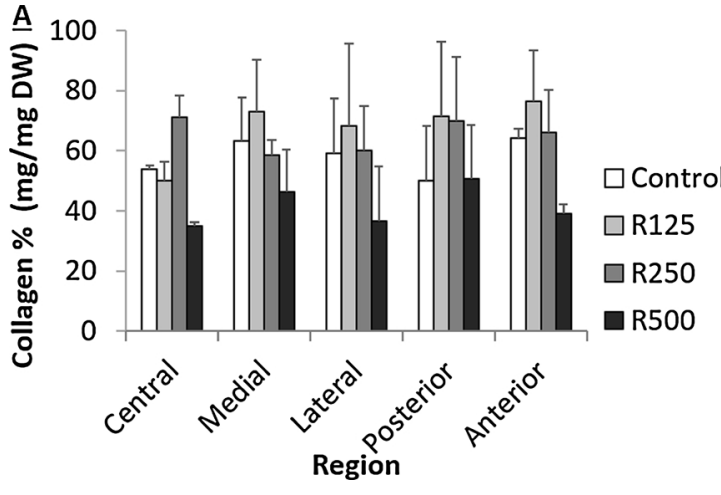

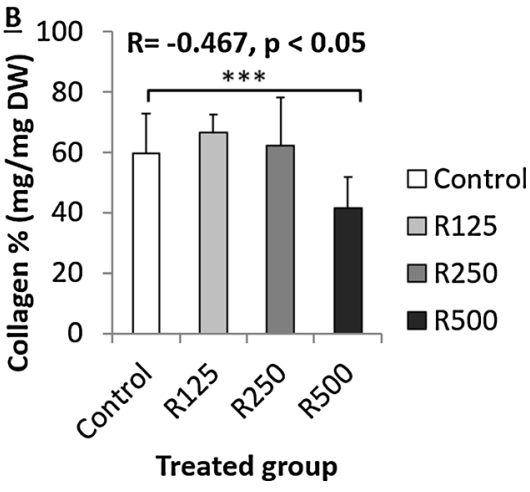

Fig. 5. Collagen content of different regions. Regional (A) and overall (B) collagen content for different ribose concentrations. There was a significant negative correlation between overall collagen content and ribose concentration (Pearson correlation analysis). Samples incubated with R500 showed significantly lower collagen content (oneway ANOVA, ${ }^{* * *} \mathrm{p}<.001$ ).
II antibodies (Fig. 7A, B). In line with the Picrosirius red stained sections (see Fig. 6) confocal microscopy revealed a disorganized orientation of the collagen fibers. Confocal microscopy images also confirmed that the disorganization in collagen fibers observed in histological sections was not due to tissue processing.

\section{Discussion}

The present study investigated the aging-like effect of ribose-induced crosslinking on the crosslink level of collagen and the concomitant effect on biomechanical characteristics of the TMJ condylar cartilage. Ribose incubation significantly correlated with the number of collagen crosslinks, approximated with Pen, and the compressive stiffness. The level of Pen as a measure of AGEs showed a significant positive correlation with the increasing ribose concentrations. The rise in Pen was in line with those reported in previous studies (Bank et al., 1998; DeGroot et al., 1999; DeGroot et al., 2001b; Vos et al., 2012a;
Willett et al., 2012). Bank et al. measured about 50 times more Pen in human articular cartilage after its incubation with $600 \mathrm{mM}$ ribose for $86 \mathrm{~h}$; the increase in Pen level measured in our study was similar to the increase they obtained in a shorter time with a comparable ribose concentration. A possible explanation for this different level of Pen could be the difference in tissue types. We used TMJ condylar cartilage; a cartilage quite different from articular cartilage: fibrocartilage versus hyaline cartilage. In other words, it contains both collagen type I and type II In contrast to hyaline cartilage, collagen type I can be detected throughout the TMJ condylar cartilage (Almarza \& Athanasiou, 2004). Although both collagen type I and II are fibrillar collagens, Antipova and Orgel (2010) have shown that collagen type II has more possible interfibrillar crosslinking sites than collagen type I. Collagen type II has similar peptide chains in its triple helical structure with three lysine groups for interfibrillar crosslinking, whereas collagen type I has different peptide chains of which only two can provide potential crosslinking sites (Antipova \& Orgel, 2010). We speculate that these
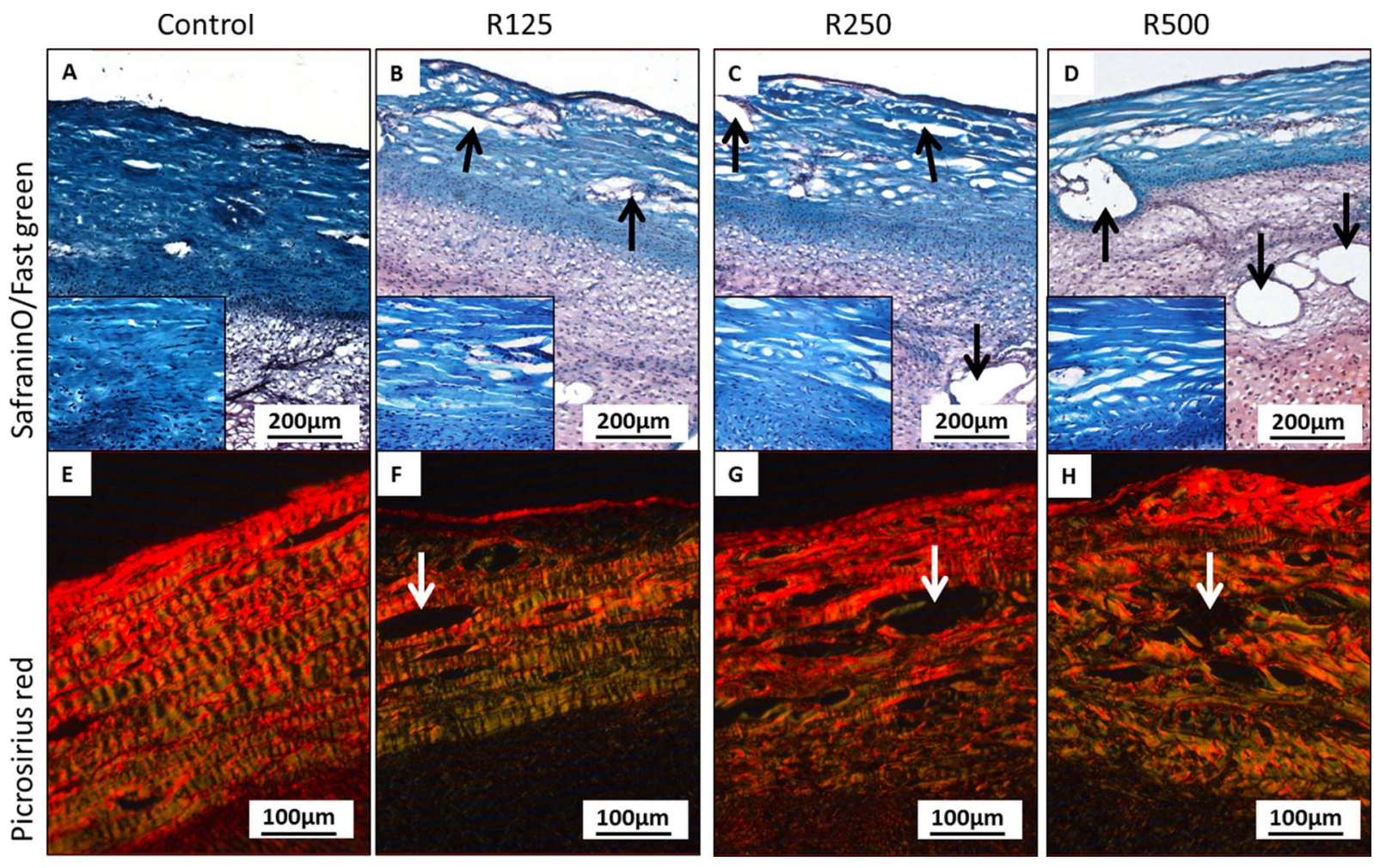

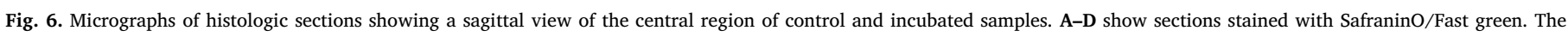

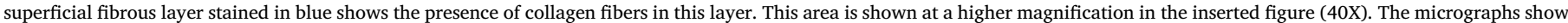

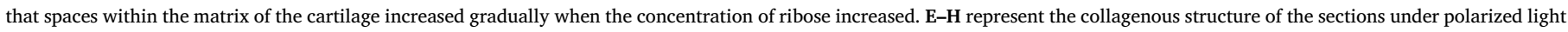

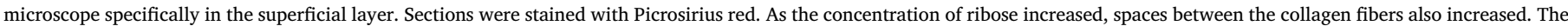

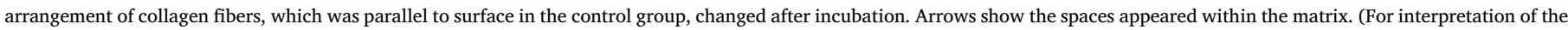
references to colour in this figure legend, the reader is referred to the web version of this article.) 


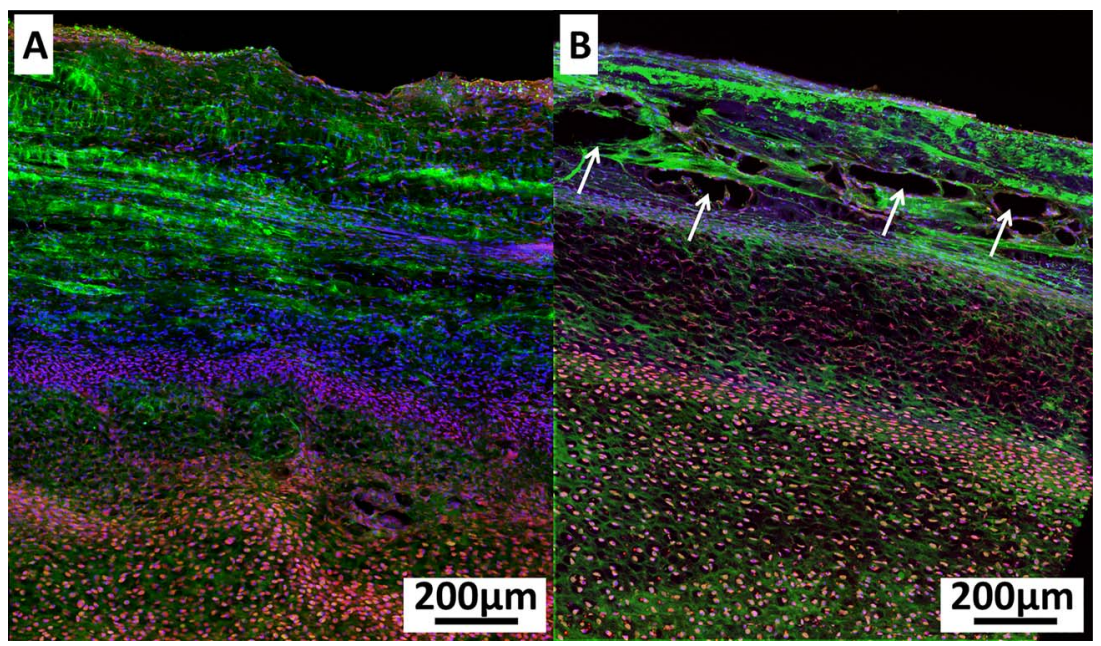

Fig. 7. Confocal microscopy of the central region from the control group (A), and the central region of the R500 group (B). Thick samples, that stained for collagen type I (green), II (red), and nuclei (blue) showed disorganization in the collagen fibers specifically in the superficial layer in the incubated sample in comparison to the control. Arrows show the spaces appeared within the matrix. (For interpretation of the references to colour in this figure legend, the reader is referred to the web version of this article.) differences in collagen molecular structure may create the different results in the crosslinking with ribose. Another reason could be the difference in the tissue's exposure to sugar. As Bank and coworkers have used small cartilage plugs rather than the intact joint that was used here, the tissue plugs were exposed to ribose solution from different directions, whereas the intact condyle was exposed to the solution only from the surface. The method used in the present study is more mimicking the in vivo situation than the method in which tissue plugs are used.

The results of stiffness measurement depicted that $\mathrm{E}_{\text {Ins }}$ and $\mathrm{E}_{\mathrm{St}}$ were region-dependent; a finding in line with previous studies (Lamela, Pelayo, Ramos, Fernández-Canteli, \& Tanaka, 2013; Lu, Mow, \& Guo, 2009; Tanaka et al., 2014). The stiffness in compressive loading is thought to be due to the presence of the negatively charged proteoglycans, which are able to trap water and thus contribute to the cartilage viscosity (Kuroda et al., 2009). A recent study has also shown that the compressive properties of the tissue are determined by the Pen amount for both artificially induced and naturally occurring crosslinks (Julkunen et al., 2009). Moreover, after ribose incubation, roughly $10 \%$ of the detected crosslinks belonged to proteoglycans (Bank et al., 1998). These findings suggested that compressive properties of articular cartilage during maturation and aging were controlled not only by proteoglycan content but also by Pen. Our results confirm that there is also such a correlation between Pen and compressive stiffness in fibrocartilaginous TMJ condyle.

During AGE formation, crosslinks are created particularly between lysine and arginine residues of collagen molecules (Sell \& Monnier, 1989). It has been assumed that collagen crosslinking makes the whole collagen network stiffer; however, it has been recently indicated that it is not the collagen network but sliding capacity in the fiber at the fibril level is influenced. The fibril sliding in the fiber of tendon collagen was reduced remarkably after getting more crosslinks (Li, Fessel, Georgiadis, \& Snedeker, 2013). Fessel et al. also showed that the induction of more crosslinks does not influence the stiffness of the collagen fibers in tendon, but instead alters fiber-fiber and fibril-fibril sliding which consequently influences the mechanical response (Fessel et al., 2014; Gautieri et al., 2017). The same explanation could be extrapolated to the results of TMJ condylar cartilage, in which the dominant collagen is type I, specifically in the superficial fibrous layer. This layer of the TMJ condylar cartilage plays an important role in its compressive and friction properties (Lu et al., 2009; Ruggiero et al., 2015).

The above-mentioned effects of crosslinking on fibrils are also in good agreement with our microscopic observations, which showed a dramatic change in the fibrous layer of condylar cartilage after incubation with ribose. It has been observed that inter-fibrillar crosslinks were created due to diabetes or following incubation with a sugar, and that those crosslinks caused closer packing of several fibrils (Bai et al., 1992; Odetti et al., 2000). We therefore assumed that, due to the packing of fibrils in some areas, more Pen can result in the shrinkage in some areas and the formation of spaces in neighboring areas (arrows in Figs. 5 and 6).

It is known that in OA, the collagen network is damaged at early stages; this damage can further lead to proteoglycan loss. Therefore, structural changes of collagen related to the increase in Pen level as shown here may result in the onset or progression of OA as it has been shown by De Groot et al. (DeGroot et al., 2004). In contrast, at the late stage of OA, the amount of AGEs was inversely correlated with cartilage damage, most probably due to an altered collagen and proteoglycan turnover rate in OA (Vos et al., 2012b).

Surprisingly, when Pen increased, a reduction in the amount of GAG as an indicator of the level of proteoglycans was observed. However, this reduction in GAG content did not reflect the aging-associated reduction in GAG which has been previously shown (Kuroda et al., 2009). Firstly, the water content which has a direct correlation with the amount of proteoglycans did not change (see Supplementary material). Secondly, it has been shown that after the creation of crosslinks in cartilaginous matrix, about $10 \%$ of detected Pen in the tissue was derived from proteoglycans (Bank et al., 1998). This means that proteoglycans were also involved in crosslinking reactions which could result in a lower digestibility. Therefore, we assume that the decrease in the amount of GAG was due to differences in the digestibility of crosslinked proteoglycans. The same reasoning as mentioned above for GAG reduction can apply to the observed reduction in collagen because the molecular solubility of collagen decreases by an accumulation of AGE (Wilson et al., 2014). Kulmala et al. have also reported a reduction in the collagen content after incubation of the articular cartilage with threose (Kulmala et al., 2013). Crosslinking has also been shown to decrease the susceptibility of articular cartilage to enzymatic digestion (DeGroot et al., 2001b; Ghazanfari, Driessen-Mol, Bouten, \& Baaijens, 2016).

It has been demonstrated that compressive properties of the superficial layer in the TMJ condyle play an important role in interstitial fluid pressurization (IFP). IFP provides around 90\% of tissue support under applied load (Ruggiero et al., 2015). AGE production reactions modify free amino groups of the collagen molecules and other proteins in the tissue matrix (Sell \& Monnier, 1989). These modifications change the fixed charge density and its distribution within the matrix, thereby influencing the tertiary structure of collagen molecules, the interactions of collagen with other proteins and water, and the fluid pressure resulting from fixed charge density in the matrix (DeGroot et al., 1999). Our results demonstrated a clear increase in compressive stiffness, 
concomitant with a rise in Pen level as well as structural changes in the fibrous layer of the condyles. The potential correlation between our finding in this study and the fixed charge density of proteoglycans, permeability, IFP, and loading distribution within the condylar cartilage provides more insights into the mechanism behind the aging-like effect of crosslinking on tissue function.

Although our study provided insights into biomechanical and biochemical consequences of AGE formation in the TMJ condylar cartilage, it had some limitations that should be considered. First, ribose used in this study can induce only an effect of collagen crosslinking. Although this method has been used widely, there are several other parameters which can influence the mechanical responses in the cartilaginous matrix. Moreover, there are some contradictory results which noted that crosslinking had a different effect than aging on collagen structure. Belkacem et al. have found that ribose incubation increased collagen fibril diameter, while aged samples have shown an overall reduction in their collagen fibril diameter (Aït-Belkacem et al., 2012).

Second, the condyles used in the present study were from young pigs in maturation stage, which undergo enzymatic crosslinking. Even though the enzymatic and non-enzymatic reactions have different routes, it might have an influence on crosslinking of the collagen molecules. The obtained results were not compared with results from naturally aged samples. Such a comparison can give a better insight into the differences and the similarities of the aging model in this study on biomechanical responses.

Thirdly, the increase in the collagen crosslinking correlated significantly with moduli ratios in our study. However, the individual regions did not show a significant increase in modulus both for steady state and instantaneous. Since the moduli of the R500 samples were always higher than for the other groups, it can be the small number of samples used for the experiments which did not result in significant differences.

Finally, some assumptions were made in mechanical characterization which can influence the results, e.g., the average of the last five reaction force cycles was used to calculate the steady state modulus. In addition, the edge effect of indenter on measured stiffness was neglected assuming that the effect is the same in all experiments.

In conclusion, an ex vivo crosslinking method was used to stimulate AGE formation and to examine the effect of crosslinking on biomechanical properties of the TMJ condylar cartilage without other agerelated alterations. Incubation with ribose correlated significantly with the amount of Pen and stiffness. The accumulation of AGEs not only influenced the compressive properties of the tissue but also the structure of the tissue itself. Although our approach does not mimic all aspects of aging, it can be considered as a practical model for simulating age-related (mechanical) changes in the TMJ condyle. Our findings are important since TMJ condyle has a unique structure among other loadbearing articular joints in which tissue matrix contains collagen type I throughout the cartilage.

\section{Conflict of interest}

None.

\section{Acknowledgments}

This research was funded by the European Commission through move-age, an Erasmus Mundus Joint Doctorate programme (20110015). The authors would like to thank Sepanta Fazaeli and Kamran Nazmi for their technical help.

\section{Appendix A. Supplementary data}

Supplementary data associated with this article can be found, in the online version, at https://doi.org/10.1016/j.archoralbio.2017.12.010.

\section{References}

Aït-Belkacem, D., Guilbert, M., Roche, M., Duboisset, J., Ferrand, P., Sockalingum, G., Brasselet, S. (2012). Microscopic structural study of collagen aging in isolated fibrils using polarized second harmonic generation. Journal of Biomedical Optics, 17(8), 0805061-0805063.

Almarza, A. J., \& Athanasiou, K. A. (2004). Design characteristics for the tissue engineering of cartilaginous tissues. Annals of Biomedical Engineering, 32(1), 2-17.

Antipova, O., \& Orgel, J. P. R. O. (2010). In situ D-periodic molecular structure of type II collagen. Journal of Biological Chemistry, 285(10), 7087-7096.

Athanasiou, K. A., Almarza, A. J., Detamore, M. S., \& Kalpakci, K. N. (2009). Tissue engineering of temporomandibular joint cartilage (1st ed.). Morgan \& Claypool [Chapter3].

Bai, P., Phua, K., Hardt, T., Cernadas, M., \& Brodsky, B. (1992). Glycation alters collagen fibril organization. Connective Tissue Research, 28(1-2), 1-12.

Bank, R. A., Jansen, E. J., Beekman, B., \& te Koppele, J. M. (1996). Amino acid analysis by reverse-phase high-performance liquid chromatography: Improved derivatization and detection conditions with 9-fluorenylmethyl chloroformate. Analytical Biochemistry, 240(2), 167-176.

Bank, R. A., Bayliss, M. T., Lafeber, F. P., Maroudas, A., \& Tekoppele, J. M. (1998). Ageing and zonal variation in post-translational modification of collagen in normal human articular cartilage. The age-related increase in non-enzymatic glycation affects biomechanical properties of cartilage. The Biochemical Journal, 330(1), 345-351.

Basser, P. J., Schneiderman, R., Bank, R. A., Wachtel, E., \& Maroudas, A. (1998). Mechanical properties of the collagen network in human articular cartilage as measured by osmotic stress technique. Archive of Biochemistry and Biophysics, 351(2), 207-219.

Bourne, J. W., Lippell, J. M., \& Torzilli, P. A. (2014). Glycation cross-Linking induced mechanical-Enzymatic cleavage of microscale tendon fibers. Matrix Biology, 34, $179-184$.

Brüel, A., \& Oxlund, H. (1996). Changes in biomechanical properties, composition of collagen and elastin, and advanced glycation endproducts of the rat aorta in relation to age. Atherosclerosis, 127(2), 155-165.

Chen, A. C., Temple, M. M., Ng, D. M., Verzijl, N., DeGroot, J., TeKoppele, J. M., \& Sah, R. L. (2002). Induction of advanced glycation end products and alterations of the tensile properties of articular cartilage. Arthritis and Rheumtism, 46(12), 3212-3217.

DeGroot, J., Verzijl, N., Bank, R. A., Lafeber, F. P., Bijlsma, J. W., \& TeKoppele, J. M. (1999). Age-related decrease in proteoglycan synthesis of human articular chondrocytes: The role of nonenzymatic glycation. Arthritis and Rheumatism, 42(5), 1003-1009.

DeGroot, J., Verzijl, N., Budde, M., Bijlsma, J. W., Lafeber, F. P., \& TeKoppele, J. M. (2001a). Accumulation of advanced glycation end products decreases collagen turnover by bovine chondrocytes. Experimental Cell Research, 266(2), 303-310.

DeGroot, J., Verzijl, N., Wenting-Van Wijk, M. J., Bank, R. A., Lafeber, F. P., Bijlsma, J. W., \& TeKoppele, J. M. (2001b). Age-related decrease in susceptibility of human articular cartilage to matrix metalloproteinase-mediated degradation: The role of advanced glycation end products. Arthritis and Rheumatism, 44(11), 2562-2571.

DeGroot, J., Verzijl, N., Wenting-van Wijk, M. J., Jacobs, K. M., Van El, B., Van Roermund, P. M., ... Lafeber, F. P. (2004). Accumulation of advanced glycation end products as a molecular mechanism for aging as a risk factor in osteoarthritis. Arthritis and Rheumtism, 50(4), 1207-1215.

Fazaeli, S., Ghazanfari, S., Everts, V., Smit, T. H., \& Koolstra, J. H. (2016). The contribution of collagen fibers to the mechanical compressive properties of the temporomandibular joint disc. Osteoarthritis and Cartilage, 24(7), 1292-1301.

Fessel, G., Li, Y., Diederich, V., Guizar-Sicairos, M., Schneider, P., Sell, D. R., ... Snedeker, J. G. (2014). Advanced glycation end-Products reduce collagen molecular sliding to affect collagen fibril damage mechanisms but not stiffness. PLoS One, 9(11), e110948.

Gautieri, A., Passini, F. S., Silvan, U., Guizar-Sicairos, M., Carimati, G., Volpi, P., \& Snedeker, J. G. (2017). Advanced glycation end-products: Mechanics of aged collagen from molecule to tissue. Matrix Biology, 59, 95-108.

Ghazanfari, S., Driessen-Mol, A., Bouten, C. V., \& Baaijens, F. P. (2016). Modulation of collagen fiber orientation by strain-controlled enzymatic degradation. Acta Biomaterialia, 35, 118-126.

Ghazanfari, S., Khademhosseini, A., \& Smit, T. H. (2016). Mechanisms of lamellar col lagen formation in connective tissues. Biomaterials, 97, 74-84.

Ghazanfari, S., Driessen-Mol, A., Sanders, B., Dijkman, P. E., Hoerstrup, S. P., Baaijens, F. P., \& Bouten, C. V. (2015). In vivo collagen remodeling in the vascular wall of decellularized stented tissue-Engineered heart valves. tissue engineering. Tissue Engineering Part A, 21(15-16), 2206-2215.

Herring, S. W. (2003). TMJ anatomy and animal models. Journal of Musculoskelet Neuronal Interact, 3(4), 391-394.

Illien-Junger, S., Grosjean, F., Laudier, D. M., Vlassara, H., Striker, G. E., \& Iatridis, J. C. (2013). Combined anti-inflammatory and anti-AGE drug treatments have a protective effect on intervertebral discs in mice with diabetes. PLoS One, 8(5), e64302.

Julkunen, P., Harjula, T., Iivarinen, J., Marjanen, J., Seppanen, K., Narhi, T., \& Helminen, H. J. (2009). Biomechanical, biochemical and structural correlations in immature and mature rabbit articular cartilage. Osteoarthritis and Cartilage, 17(12), 1628-1638.

Kim, K. W., Wong, M. E., Helfrick, J. F., Thomas, J. B., \& Athanasiou, K. A. (2003). Biomechanical tissue characterization of the superior joint space of the porcine temporomandibular joint. Annals of Biomedical Engineering, 31(8), 924-930.

Kohn, R. R., Cerami, A., \& Monnier, V. M. (1984). Collagen aging in vitro by nonenzymatic glycosylation and browning. Diabetes, 33(1), 57-59.

Koolstra, J. H. (2002). Dynamics of the human masticatory system. Critical Reviews in Oral Biology \& Medicine, 13(4), 366-376.

Kulmala, K. A., Karjalainen, H. M., Kokkonen, H. T., Tiitu, V., Kovanen, V., Lammi, M. J., Toyras, J. (2013). Diffusion of ionic and non-ionic contrast agents in articular 
cartilage with increased cross-linking-contribution of steric and electrostatic effects. Medical Engineering and Physics, 35(10), 1415-1420.

Kuroda, S., Tanimoto, K., Izawa, T., Fujihara, S., Koolstra, J. H., \& Tanaka, E. (2009). Biomechanical and biochemical characteristics of the mandibular condylar cartilage. Osteoarthritis and Cartilage, 17(11), 1408-1415.

Lamela, M. J., Pelayo, F., Ramos, A., Fernández-Canteli, A., \& Tanaka, E. (2013). Dynamic compressive properties of articular cartilages in the porcine temporomandibular joint. Journal of the Mechanical Behavior of Biomedical Materials, 23(0), 62-70.

Li, Y., Fessel, G., Georgiadis, M., \& Snedeker, J. G. (2013). Advanced glycation endproducts diminish tendon collagen fiber sliding. Matrix Biology, 32(3-4), 169-177.

Lodish, H., Berk, A., Ziporsky, S. L., Matsudaira, P., Baltimore, D., \& Darnell, J. (2000) Molecular cell biology (4th ed.). New York: W.HFreeman and Co.

Lu, X. L., Mow, V. C., \& Guo, X. E. (2009). Proteoglycans and mechanical behavior of condylar cartilage. Journal of Dental Research, 88(3), 244-248.

Mirahmadi, F., Koolstra, J. H., Lobbezoo, F., van Lenthe, G. H., \& Everts, V. (2017). Ex vivo thickness measurement of cartilage covering the temporomandibular joint. Journal of Biomechanics, 52, 165-168.

Odetti, P., Aragno, I., Rolandi, R., Garibaldi, S., Valentini, S., Cosso, L., \& Marinari, U. M. (2000). Scanning force microscopy reveals structural alterations in diabetic rat collagen fibrils: Role of protein glycation. Diabetes/ Metabolism Research and Reviews, 16(2), 74-81.

Panwar, P., Lamour, G., Mackenzie, N. C., Yang, H., Ko, F., Li, H., \& Bromme, D. (2015). Changes in structural - Mechanical properties and degradability of collagen during aging-associated modifications. The Journal of Biological Chemistry, 290(38), 23291-23306.

Paul, C. P. L., Schoorl, T., Zuiderbaan, H. A., Zandieh Doulabi, B., van der Veen, A. J., van de Ven, P. M., ... Mullender, M. G. (2013). Dynamic and static overloading induce early degenerative processes in caprine lumbar intervertebral discs. PLoS One, 8(4), e62411.

Reddy, G. K., Stehno-Bittel, L., \& Enwemeka, C. S. (2002). Glycation-induced matrix stability in the rabbit achilles tendon. Archive of Biochemistry and Biophysics, 399(2), $174-180$.

Reddy, G. K. (2004). Cross-linking in collagen by nonenzymatic glycation increases the matrix stiffness in rabbit achilles tendon. Experimental Diabesity Research, 5(2), 143-153.

Ruggiero, L., Zimmerman, B. K., Park, M., Han, L., Wang, L., Burris, D. L., \& Lu, X. L. (2015). Roles of the fibrous superficial zone in the mechanical behavior of TMJ condylar cartilage. Annals of Biomedical Engineering, 43(11), 2652-2662.

Scharf, B., Clement, C. C., Yodmuang, S., Urbanska, A. M., Suadicani, S. O., Aphkhazava, D., ... Santambrogio, L. (2013). Age-related carbonylation of fibrocartilage structural proteins drives tissue degenerative modification. Chemistry and Biology, 20(7), 922-934.

Sell, D. R., \& Monnier, V. M. (1989). Structure elucidation of a senescence cross-link from human extracellular matrix. Implication of pentoses in the aging process. The Journal of Biological Chemistry, 264(36), 21597-21602.

Tanaka, E., Aoyama, J., Tanaka, M., Murata, H., Hamada, T., \& Tanne, K. (2002). Dynamic properties of bovine temporomandibular joint disks change with age. Journal of Dental Research, 81(9), 618-622.

Tanaka, E., Pelayo, F., Kim, N., Lamela, M. J., Kawai, N., \& Fernandez-Canteli, A. (2014). Stress relaxation behaviors of articular cartilages in porcine temporomandibular joint. Journal of Biomechanics, 47(7), 1582-1587.

Tang, S. Y., Zeenath, U., \& Vashishth, D. (2007). Effects of non-enzymatic glycation on cancellous bone fragility. Bone, 40(4), 1144-1151.

Verzijl, N., DeGroot, J., Thorpe, S. R., Bank, R. A., Shaw, J. N., Lyons, T. J., \& TeKoppele, J. M. (2000). Effect of collagen turnover on the accumulation of advanced glycation end products. The Journal of Biological Chemistry, 275(50), 39027-39031.

Verzijl, N., DeGroot, J., Ben, Z. C., Brau-Benjamin, O., Maroudas, A., Bank, R. A., .. TeKoppele, J. M. (2002). Crosslinking by advanced glycation end products increases the stiffness of the collagen network in human articular cartilage: A possible mechanism through which age is a risk factor for osteoarthritis. Arthritis and Rheumtism, 46(1), 114-123.

Vos, P. A. J. M., DeGroot, J., Barten-van Rijbroek, A. D., Zuurmond, A. M., Bijlsma, J. W., Mastbergen, S. C., \& Lafeber, F. P. (2012a). Elevation of cartilage AGEs does not accelerate initiation of canine experimental osteoarthritis upon mild surgical damage. Journal of Orthopaedic Research, 30(9), 1398-1404.

Vos, P. A. J. M., Mastbergen, S. C., Huisman, A. M., de Boer, T. N., DeGroot, J., Polak, A. A., \& Lafeber, F. P. J. G. (2012b). In end stage osteoarthritis, cartilage tissue pentosidine levels are inversely related to parameters of cartilage damage. Osteoarthritis and Cartilage, 20(3), 233-240.

Willems, N. M., Langenbach, G. E., Stoop, R., den Toonder, J. M., Mulder, L., Zentner, A., \& Everts, V. (2014). Higher number of pentosidine cross-links induced by ribose does not alter tissue stiffness of cancellous bone. Materials Science and Engineering: C, 42, 15-21.

Willett, T. L., Kandel, R., De Croos, J. N. A., Avery, N. C., \& Grynpas, M. D. (2012). Enhanced levels of non-enzymatic glycation and pentosidine crosslinking in spontaneous osteoarthritis progression. Osteoarthritis and Cartilage, 20(7), 736-744.

Wilson, S. L., Guilbert, M., Sulé-Suso, J., Torbet, J., Jeannesson, P., Sockalingum, G. D., \& Yang, Y. (2014). A microscopic and macroscopic study of aging collagen on its molecular structure, mechanical properties, and cellular response. The FASEB Journal, 28(1), 14-25. 